\title{
Effect of bile acid perfusion on colonic motor function in patients with the irritable colon syndrome
}

\author{
I TAYLOR, P BASU, P HAMMOND, C DARBY, AND M FLYNN \\ From the Departments of Surgery and Bioengineering, University of Liverpool, Liverpool
}

SUMMARY A study was performed to determine the effect of bile acid perfusion on motility in the sigmoid colon of patients with the irritable colon syndrome compared with normal subjects. Deoxycholic acid (15 mM) statistically significantly increased motility in normal subjects (control $25.0 \pm$ $6.4 \%$, perfusion $71 \cdot 4 \pm 7.2 \%, P<0.05$ ) but neither chenodeoxycholic acid nor cholic acid had any apparent effect. In patients with the irritable colon syndrome, however, deoxycholic acid at $5 \mathrm{mM}$ concentration (control $29.8 \pm 4.2 \%$, during perfusion $57.4 \pm 6.5 \%, \mathrm{P}<0.05$ ) as well as at $15 \mathrm{mM}$ concentration (control $19.4 \pm 5.7 \%$, perfusion $57.8 \pm 9.6 \%, \mathrm{P}<0.05$ ) statistically significantly increased rectosigmoid motility. Patients with the irritable colon syndrome had a high resting $0.033-$ $0.066 \mathrm{~Hz}(2-4 \mathrm{c} / \mathrm{m})$ electrical activity, whereas in normal subjects $0.1-0.15 \mathrm{~Hz}(6-9 \mathrm{c} / \mathrm{m})$ activity was greater. However, there was no statistically significant alteration in either electrical rhythm during the period of bile acid perfusion. In conclusion, additional evidence is presented to suggest that deoxycholic acid is the only bile acid likely to be implicated in the motor disorder of the irritable colon syndrome.

The fundamental abnormality in the irritable colon syndrome remains obscure. The typical history is of relapses and remissions with pain and bowel symptoms (alternating between constipation and diarrhoea). It has been suggested that an abnormality in small bowel function-both motility ${ }^{1}$ and absorption $^{2}$ also occurs in this condition, and so the term 'irritable bowel syndrome' has been used in preference to the 'irritable colon syndrome'. However, motility disturbances undoubtedly occur in the colon of patients with this abnormality ${ }^{3}$ and, more recently, myoelectrical disturbances have also been recognised. ${ }^{45}$

Recent evidence has accumulated to suggest that bile acids are themselves capable of altering colonic function. All bile acids inhibit absorption ${ }^{6}$ and it has previously been shown that deoxycholic acid $(15 \mathrm{mM})$ stimulates motility in the dog in vivo ${ }^{7}$ and human colon in vitro. It is feasible that in patients with the irritable colon syndrome an altered sensitivity of colonic smooth muscle to luminal bile acids is present. Hence bile acids in contact with colonic smooth muscle may alter motor function and result in symptoms of the irritable colon syndrome. In order to test this hypothesis, a double-

Received for publication 13 May 1980 blind study was initiated in which varying concentrations of different bile acids (both primary and secondary) were separately infused into the sigmoid colon of both normal subjects and patients with the irritable colon syndrome and the motility responses were compared.

\section{Methods}

Thirty patients referred with symptoms typical of the irritable colon syndrome for at least 18 months were studied. Each patient had been extensively investigated over this period and no obvious organic abnormality had been detected. Some had previously been treated with antispasmodics and others with high fibre diet. They were compared with an age- and sex-matched group of 30 normal subjects with no history of gastrointestinal pathology. In each subject sigmoidoscopy was performed and a thin $2 \mathrm{~mm}$ internal diameter tube was positioned into the sigmoid colon for constant perfusion with either normal saline or a bile acid solution at $37^{\circ} \mathrm{C}$. An intraluminal suction electrode was then positioned into the rectosigmoid region (at least $15 \mathrm{~cm}$ from the anus) for continuous measurements of electrical activity. ${ }^{8}$ Incorporated into this main tube was a thin open-ended tube constantly perfused with 


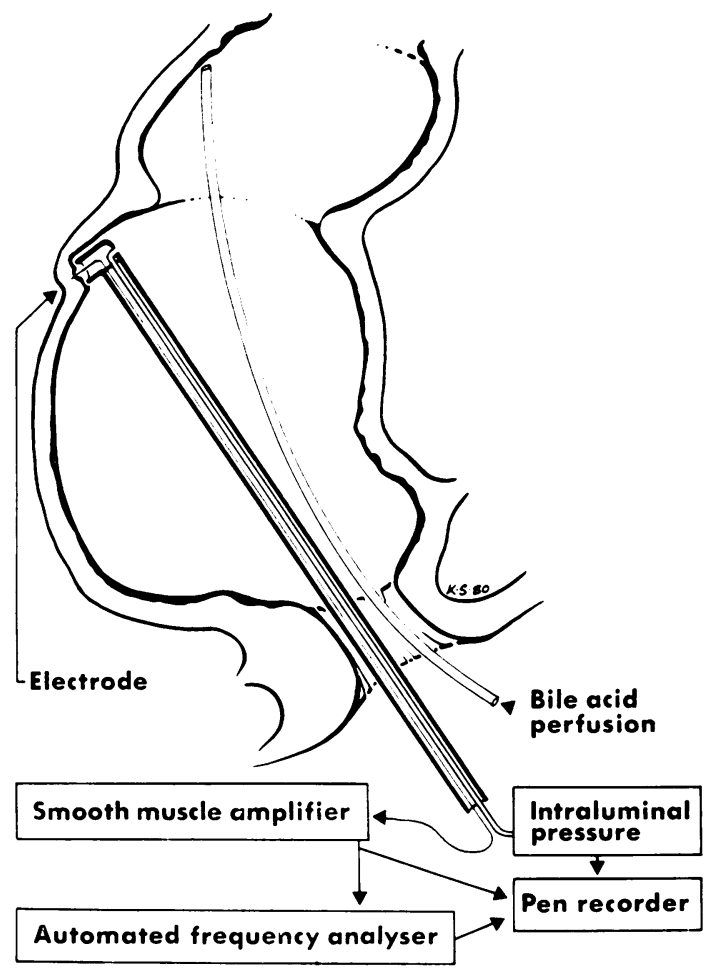

Fig. 1 Diagramatic representation of positioning of tubes in rectosigmoid region.

normal saline and used for measurement of changes in intraluminal pressure (Fig. 1).

\section{ELECTRICAL ACTIVITY}

After allowing the effect of insertion of the tube to pass (at least 15 minutes) monopolar electrical recordings were obtained from the suction electrode using an indifferent electrode placed on the scarified skin on the right thigh. The electrical signals were suitably amplified and the electrical slow wave was characterised by means of a purpose-built frequency spectrum analyser as previously described. ${ }^{8}$ The frequency of each electrical rhythm was measured as well as the proportion of the total recording time that each rhythm was present.

INTRALUMINAL PRESSURE

Changes in intraluminal pressure were obtained by means of the thin open-ended tube incorporated in the main suction device, which was then attached to a pressure transducer. The basal pressure in $\mathrm{mmHg}$ was noted as well as the percentage motility -that is, the proportion of total recording time that pressure waves were present.

After the period of stabilisation, recordings were obtained during perfusion of normal saline into the sigmoid colon $(0.3 \mathrm{ml} / \mathrm{min})$ at $37^{\circ} \mathrm{C}$. Each subject was then randomally allocated to receive a bile acid solution which was perfused at the same rate. The actual bile acid was not known to the investigator and the recordings were subsequently analysed without knowledge of the bile acid being perfused. The sodium salts of the following bile acids were studied; deoxycholic (5 and $15 \mathrm{mM}$, pH 9.5), chenodeoxycholic (5 and $15 \mathrm{mM}$, pH 9.5), cholic acid (5 and $15 \mathrm{mM}, \mathrm{pH} \mathrm{7.7)}$. All bile acids had an osmolality of $30 \mathrm{~m} 0 \mathrm{sm} / \mathrm{kg}$. Previous studies have shown motility to be unaffected by $\mathrm{pH}$.

Recordings were obtained for at least 30 minutes and the responses during the saline and bile acid perfusion were compared. Each bile acid solution was administered to five normal subjects and five patients with the irritable colon syndrome. The concentrations of bile acids used were physiological, as previous measurements of faecal bile acid excretion (using gas liquid chromatography) in the irritable colon syndrome had resulted in mean concentration of deoxycholic acid excretion of $7.0 \mathrm{mM}$ (range 1.9-18 $\mathrm{mM}$ ) in normal subjects and $4.0 \mathrm{mM}$ (range 1.6-9.3 $\mathrm{mM}$ ) in patients with the irritable colon syndrome.

The data was analysed using standard statistical analysis and paired $t$ tests.

\section{Results}

INTRALUMINAL PRESSURE

The mean basal pressure in normal subjects was $15.0 \pm 1.6 \mathrm{mmHg}$ and $21.6 \pm 2.4 \mathrm{mmHg}$ in patients with the irritable colon syndrome. Similarly, there was no statistically significant difference in mean percentage motility between normal subjects (mean $19 \cdot 2 \pm 2 \cdot 6 \%)$ and patients with the irritable colon syndrone (mean $18.8 \pm 1.9 \%$ ).

\section{NORMAL SUBJECTS}

During perfusion of both cholic acid and chenodeoxycholic acid at each concentration no statistically significant alteration in motility was noted compared with values obtained during the saline perfusion (Fig. 2). However, during deoxycholic acid administration at $15 \mathrm{mM}$ concentration, a statistically significant rise in percentage motility occurred (during saline perfusion mean 25.0土 $6.4 \%$; during deoxycholic acid perfusion mean $71.4 \pm 7.2 \%, \quad P<0.05$ ) (Fig. 3). No statistically significant difference was found in mean basal pressure during perfusion of each solution. 
Fig. 2 Top traces show the frequency analysis of the slow wave electrical recording and intraluminal pressure changes during saline perfusion in a normal subject. No statistically significant changes have occurred in these parameters during perfusion with $15 \mathrm{mM}$ cholic acid (bottom traces).

\section{IRRITABLE COLON SYNDROME}

Similarly, in patients with the irritable colon syndrome, no statistically significant change in motility occurred during perfusion with either chenodeoxycholic acid or cholic acid at either concentration. However, during deoxycholic acid perfusion, the mean percentage motility (Fig. 4) showed a statistically significant rise both for $5 \mathrm{mM}$ (resting mean $29 \cdot 8 \pm 4.2 \%$ and during perfusion mean $57 \cdot 4 \pm 6.5 \%$, $\mathbf{P}<0.05$ ) as well as $15 \mathrm{mM}$ concentration (saline perfusion $19 \cdot 4 \pm 5 \cdot 7 \%$ during perfusion $57 \cdot 8 \pm$ 9.6\%, P<0.05) (Fig. 5).

In addition, four patients claimed that perfusion with deoxycholic acid (two with $5 \mathrm{mM}$ and two with $15 \mathrm{mM}$ ) stimulated typical symptoms of mild pain in the left iliac fossa and the desire for urgent defaecation. No other bile acid had this effect.

\section{ELECTRICAL ACTIVITY}

In patients with the irritable colon syndrome there was a statistically significantly greater incidence of 2-4 c/m (0.033-0.066 Hz) compared with normal subjects $(58 \cdot 6 \pm 3 \cdot 0 \%$, normal subjects $37 \cdot 7 \pm 3 \cdot 7 \%$ $\mathbf{P}<0.001)$. In addition, the mean percentage incidence of $6-9 \mathrm{c} / \mathrm{m}(0 \cdot 1-0.15 \mathrm{~Hz})$ activity was greater in normal subjects than patients with the irritable
Control - Normal subject

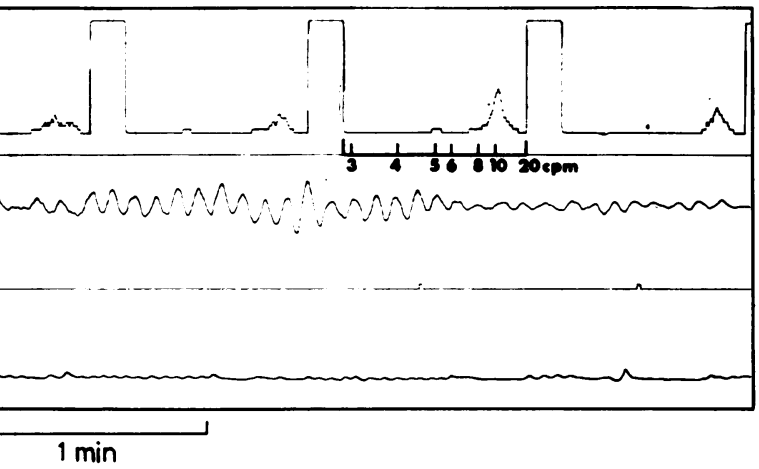

$15 \mathrm{mM}$ Cholic acid perfusion - Normal subject drome $36.8 \pm 3.9 \%, P<0.01)$. During perfusion of each bile acid solution, no statistically significant change occurred in either the mean frequency or percentage incidence of the electrical rhythms in either normal subjects or patients with the irritable colon syndrome.

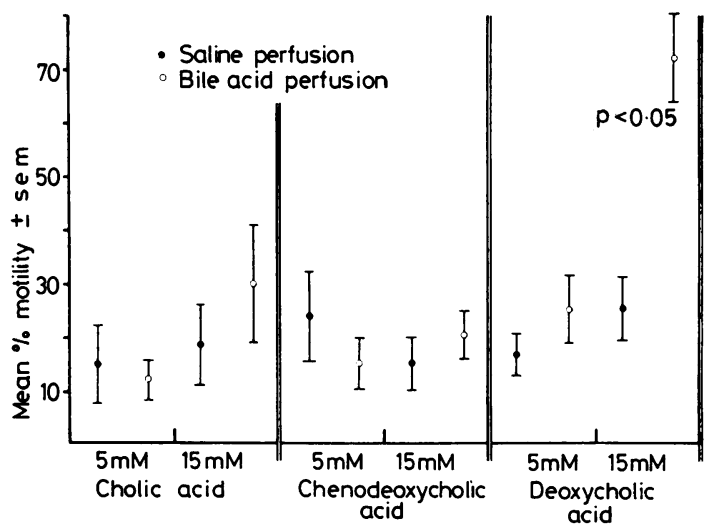

Fig. 3 Mean percentage motility in normal subjects during perfusion with saline and different bile acids. Note that only $15 \mathrm{mM}$ deoxycholic acid shows a statistically significant increase in percentage motility. 


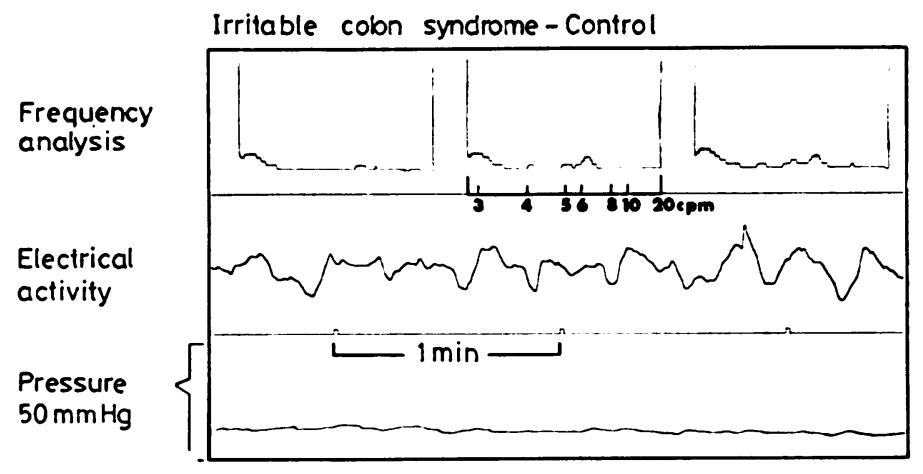

$5 \mathrm{mM}$ Deoxycholic acid-Irritable colon syndrome

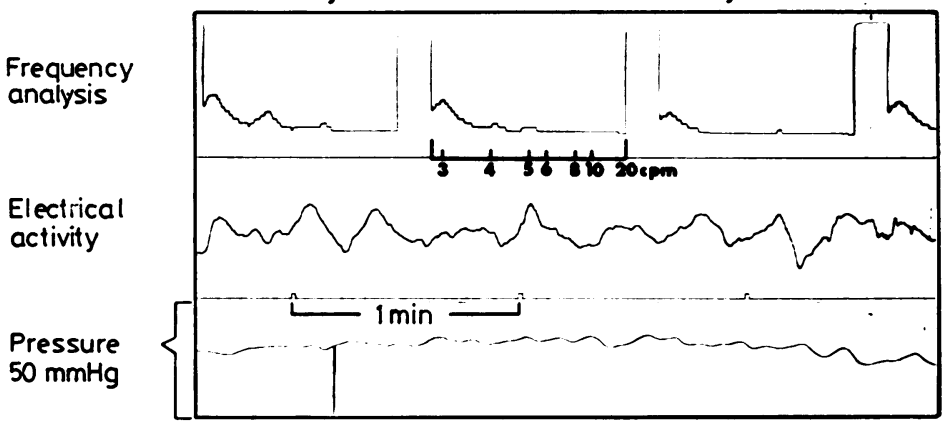

Fig. 4 Top traces show the frequency analysis of the slow wave electrical recording and intraluminal pressure changes during saline perfusion in a patient with the irritable colon syndrome. Note the marked increase in motility during perfusion with $5 \mathrm{mM}$ deoxycholic acid. However, no apparent alteration in either frequency or amplitude of the $0.05 \mathrm{~Hz}(3 \mathrm{c} / \mathrm{m})$ electrical activity occurs.

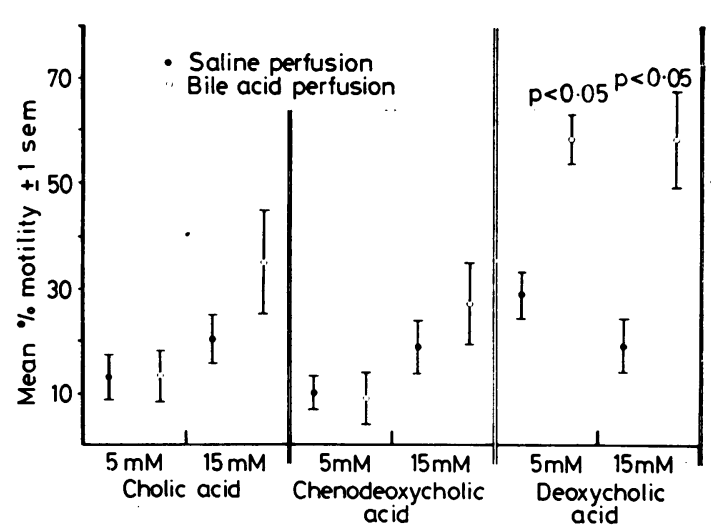

Fig. 5 Mean percentage motility in patients with the irritable colon syndrome during perfusion with saline and different bile acids. Note that both $5 \mathrm{mM}$ and $15 \mathrm{mM}$ concentrations of deoxycholic acid result in a statistically significant increase in percentage motility. No changes were noted with either cholic or chenodeoxycholic acid.

\section{Discussion}

Bile acids are known to inhibit colonic absorption and this property may be responsible for the diar- rhoea after terminal ileal resection during which large quantities of unabsorbed bile acids enter the colon. The role of bile acids, however, on colonic motility is still the subject of much debate. In Thiry-Vella loops of dog colon only deoxycholic acid (15 mM concentration) stimulated motility with no apparent change in myoelectrical activity. Similar results have been demonstrated in rabbit colon and in man. ${ }^{9}$ The colon is known to absorb bile acids ${ }^{10}$ and hence aids in recirculation. In addition, colonic bacterial flora converts primary to secondary bile acids ${ }^{10}$ resulting in faecal excretion of lithocholic acid and deoxycholic acid. It seems reasonable to postulate that, if bile acids are to be implicated in motor disorders of the colon, these two secondary bile acids should be involved.

Faecal bile acid excretion in the irritable colon syndrome is controversial, although in a recent study ${ }^{11}$ with repeated estimations measured over a one year period statistically significantly lower levels of deoxycholic acid were found in patients with the irritable colon syndrome. Hence, it would seem that deoxycholic acid is capable of being absorbed to a greater extent by the colon in patients suffering from the irritable colon syndrome and hence greater concentrations of the bile acid will 
come into contact with colonic smooth muscle for a longer period of time. This may result in the characteristic slow wave electrical pattern recognised in patients with the irritable colon syndrome. ${ }^{45}$

In the present study, different concentrations of bile acids were perfused 'blind' into the sigmoid colon of both normal subjects and patients with the irritable colon syndrome. Only deoxycholic acid was found to stimulate colonic motility and did so in both normal subjects and patients with the irritable colon syndrome. However, in the latter group of patients a lower concentration $(5 \mathrm{mM})$ led to a stimulatory effect compared with normal subjects when only $15 \mathrm{mM}$ was effective. It would seem therefore that colonic smooth muscle in patients with the irritable colon syndrome is 'sensitive' to a lower concentration of deoxycholic acid and is able to stimulate colonic motility.

There are a number of possible factors which could mediate this response. Firstly, deoxycholic acid increases membrane permeability and hence may increase intracellular $\mathrm{Ca}^{2+}$ ion concentration. ${ }^{12}$ In addition, deoxycholic acid could potentiate the effects of cholinergic agonists. ${ }^{13}$ Glycocholate has been shown to remove cholinesterase from red cell membranes ${ }^{14}$ and, as deoxycholate is an even stronger detergent, this bile acid may also remove cholinesterase from smooth muscle cell membranes and hence prolong the action of acetylcholine.

In conclusion, additional evidence is produced to implicate deoxycholic acid as a possible factor in the aetiology of the irritable colon syndrome.

We would like to thank the nursing staff of the Gastroenterology Unit at Broadgreen Hospital for their assistance in the performance of these studies. A grant was awarded by the MRHA research committee for the performance of this study.

\section{References}

${ }^{1}$ Milton-Thompson GJ, Cummings JH, Newman A, Billings JA, Misiewicz JJ. Colonic and small intestine response to intravenous prostaglandin $F_{2 a}$ and $E_{2}$ in man. Gut 1975; 16: 42-6.

${ }^{2}$ Phillips SF. Diarrhea: a current view of the pathophysiology. Gastroenterology 1972; 63: 495-518.

${ }^{3}$ Chaudhary NA, Truelove SC. Human colonic motility: A comparative study of normal subjects, patients with ulcerative colitis, and patients with the irritable colon syndrome. Gastroenterology $1961 ; 40$ : 1-36.

${ }^{4}$ Snape WJ Jr, Carlson GM, Matarazzo SA, Cohen S. Evidence that abnormal myoelectrical activity produces colonic motor dysfunction in the irritable bowel syndrome. Gastroenterology 1972; 72: 383-7.

${ }^{5}$ Taylor I, Darby C, Hammond P, Basu P. Is there a myoelectrical abnormality in the irritable colon syndrome? Gut 1978; 19: 391-5.

${ }^{6}$ Mekhjian HS, Phillips SF, Hoffmann AF. Colonic secretion of water and electrolytes induced by bile acids: perfusion studies in man. J Clin Invest 1971; 50: $1569-77$.

${ }^{7}$ Flynn M, Darby C, Hyland J, Hammond P, Taylor I. The effect of bile acids on colonic myoelectrical activity. Br J Surg 1979; 66: 776-9.

${ }^{8}$ Taylor I, Darby C, Hammond P. Comparison of rectosigmoid myoelectrical activity in the irritable colon syndrome during relapses and remissions. Gut 1978; 19: 923-9.

${ }^{9}$ Kirwan WO, Smith AN, Mitchell WD, Falconer JD, Eastwood MA. Bile acids and colonic motility in the rabbit and the human. Gut 1975; 16: 894-902.

${ }^{10}$ Samuel P, Saypol GM, Meilman E, Mosbach EH, Chafizadeh, M. Absorption of bile acids from the large bowel in man. J Clin Invest 1968; 47: 2070-8.

${ }^{11}$ Flynn M, Darby C, Hammond P, Taylor I. Relationship between faecal bile acid excretion and colonic myoelectrical activity in the irritable colon syndrome. Gut 1979; 20: A946.

${ }^{12} \mathrm{Grundfest} \mathrm{H}$. The role of calcium ions in excitation contraction coupling In: Physiology of smooth muscle. Bülbring EP, Schuba MF eds New York: Raven Press, pp:163-74.

${ }^{13}$ Szurszewski JH, Bülbring E. The stimulant action of acetylcholine and catecholomines on the uterus. Physiol Trans Roy Soc Lond (Biol Sci) 1973; 265: 14956.

${ }^{14}$ Billington D, Colman R. Effects of bile salts on human erythrocytes. Plasma membrane vesiculation, phospholipid solubilization and their possible relationship to bile secretion. Biochem Biophys Acta 1978; 509: 3347. 